\title{
4.2 Психологические особенности гендерной социализации детей в детском доме в условиях карантина
}

Проблема оказания психолого-педагогической помощи детям-сиротам ставит в ряд приоритетных задач изучение вопросов, связанных с адаптацией и интеграцией воспитанников детских домов в обществе. У детей, оставшихся без попечения родителей, возможно, затруднено формирование эталонов гендерных нормативных ориентаций и стереотипов поведения. Это может быть обусловлено недостаточностью мужского/женского воспитания; недостаточностью психолого-педагогической подготовленности воспитателей по формированию гендерной идентификации воспитанников; разрывом с семьей и помещением ребенка в детский дом.

Одним из возможных способов предупреждения нарушений процесса гендерной социализации и идентификации подростков, оставшихся без попечения родителей, является изучение ее специфических особенностей, что позволит обоснованно подходить к организации гендерной социализации детей в детском доме.

В марте 2021 г. мы провели психологическое тестирование детей с целью изучения психологических особенностей гендерной социализации детей в детском доме в условиях карантина. Тестирование проводилось в онлайн формате через платформу Google. Данное исследование выполнено в рамках государственного заказа для реализации научного проекта бюджетной программы 217 «Развитие науки», подпрограммы 102 «Грантовое финансирование научных проектов» (Республика Казахстан).

В тестировании приняли участие 49 человек, из них - 27 девочек и 22 мальчика. Возраст детей, которые приняли участие в тестировании, от 9 до 17 лет (см. рисунок 1): 


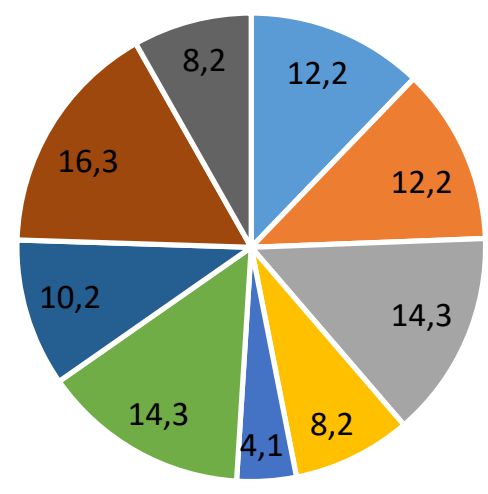

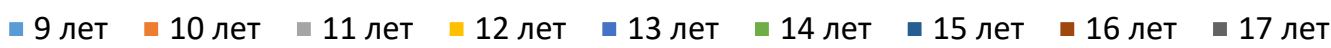

Рисунок 1. Возрастной критерий участия в тестировании, \%

Мы использовали следующие методики: Опросник «Я - мальчик / девочка...» Л. Н. Ожиговой; Полоролевой опросник (С.С. Бем); Опросник «Кто Я?» (М. Кун и Т. Макпартленд) [266, с. 2].

Опросник «Я - мальчик / девочка...» Л. Н. Ожиговой был использован с целью изучения особенностей гендерной идентичности и степени приверженности гендерным стереотипам, а ответы детей позволили раскрыть сущность того «какой я мальчик», «какая я девочка» и определить с чем себя они идентифицируют, т.е. с социальным статусом и связанными с ним чертами характера.

Полоролевой опросник С.С. Бема был использован с целью изучения степени выраженности маскулинных и фемининных характеристик девочек и мальчиков и определения полоролевых типов личности.

Опросник «Кто Я?» М. Куна и Т. Макпартленда был использован для выявления роли гендерных характеристик в структуре Я-концепции личности девочек и мальчиков, а также для изучения содержательных характеристик идентичности их личности.

Нами были получены следующие результаты. По опроснику Л. Н. Ожиговой мы определили особенности гендерной идентичности детей и степени 
приверженности гендерным стереотипам, т.е. с чем себя идентифицируют девочки и мальчики. Мы выявили следующие особенности.

Внутреннее самоощущение детей, их представления и установки относительно социальных и культурных стереотипов о поведении и качествах представителей разных гендеров выражены в соответствии с полом ребенка. Результаты представлены на рисунках 2-5.

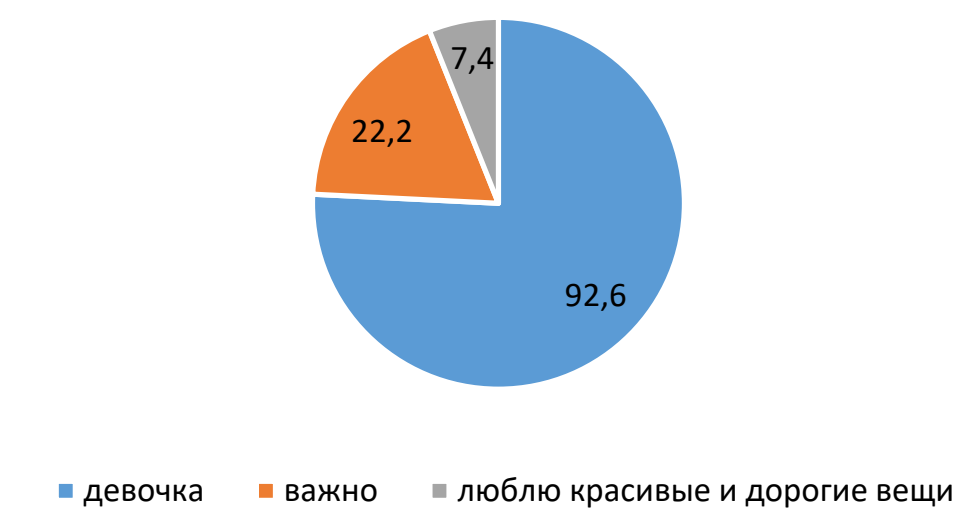

Рисунок 2. Внутреннее самоощущение девочек, \%

Из рисунка 2 мы видим, что девочки самоощущают себя как «девочка» $(96,2 \%)$ и «люблю красивые и дорогие вещи» $(7,4 \%)$. Для 22,2\% девочек это важно, остальные - не отмечают этот критерий как важный. То есть внутреннее самоощущение девочек соответствует их гендерной идентичности.

Также мы видим, что небольшой процент девочек $(7,4 \%)$ находится под влиянием социальных стереотипов о поведении девочек - это установка на то, что у девочек должны быть красивые и дорогие вещи. 
нежность

любовь

- умение постоять за себя

- забота

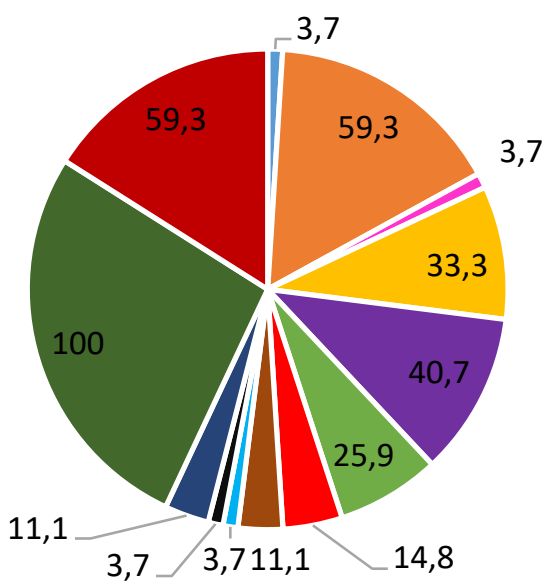

уважение

- доверие

- верность

- умение готовить

п помощь

- семья

- понимание

- красивая

\section{Рисунок 3. Представления и установки относительно социальных и} культурных полоролевых стереотипов о поведении и качествах у девочек, $\%$

Из рисунка 3 мы видим, какие представления и установки относительно социальных и культурных полоролевых стереотипов о поведении и качествах выражены у девочек. Перечень качеств, характеризующих личность и относящих ее к гендерному типу следующие.

Так, девочки должны обладать такими качествами характера, как: красивая (100\%), умение постоять за себя (14,8\%), умение готовить $(11,1 \%)$, нежность $(3,7 \%)$.

Установки относительно поведения выражаются в следующем: уважение (59,3\%), «многого в жизни добьюсь» (59,3\%), доверие (40,7\%), любовь (33,3\%), помощь $(25,9 \%)$, семья $(11,1 \%)$, понимание $(3,7 \%)$, забота $(3,7 \%)$. 


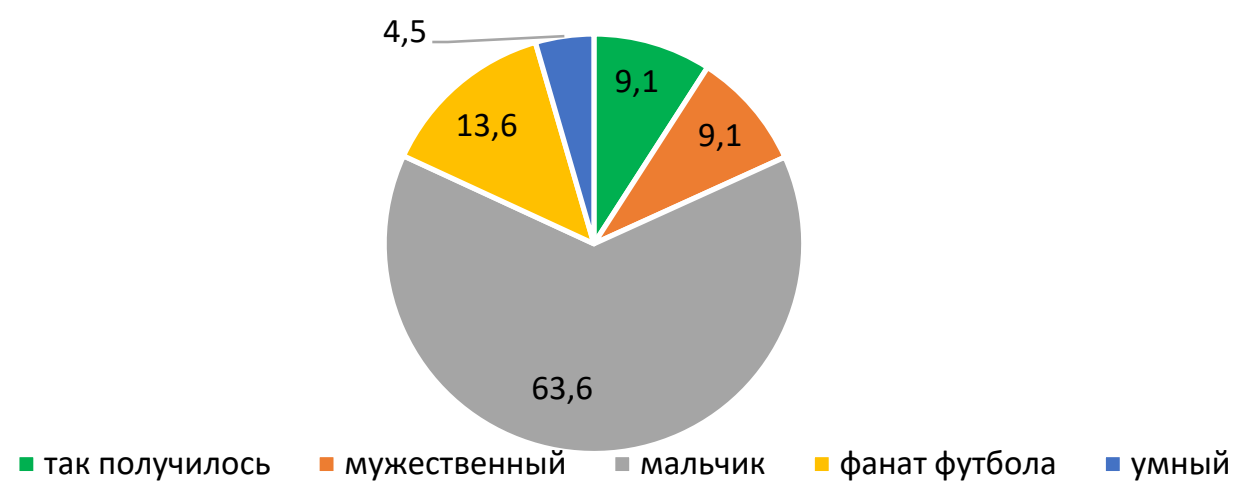

\section{Рисунок 4. Внутреннее самоощущение мальчиков, \%}

Из рисунка 4 мы видим, что мальчики самоощущают себя как «мальчик» $(63,6 \%)$, «фанат футбола» $(13,6 \%)$, «мужественный» $(9,1 \%)$ и «умный» $(4,5 \%)$. То есть у этих мальчиков внутреннее самоощущение соответствует их гендерной идентичности.

Но вместе с этим есть 9,1\% мальчиков, которые отмечают - «так получилось». Это может говорить о том, что эти дети находятся в трудной жизненной ситуации и выполнять социальные установки относительно стереотипов мужского поведения и мужских качествах им в настоящий период времени достаточно сложно и нелегко.

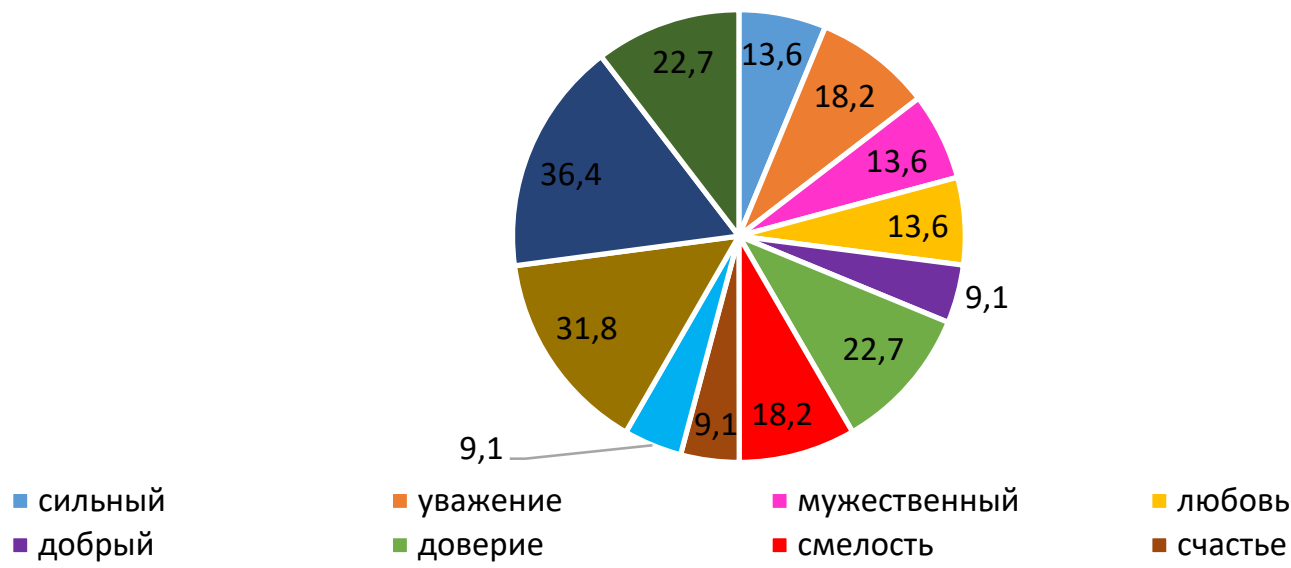

Рисунок 5. Представления и установки относительно социальных и культурных полоролевых стереотипов 0 поведении и качествах мальчиков, \% 
Из рисунка 5 мы видим, какие представления и установки относительно социальных и культурных полоролевых стереотипов о поведении и качествах выражены у мальчиков.

Перечень качеств, характеризующих личность и относящих ее к гендерному типу следующие. Так, мальчики должны обладать такими качествами характера, как: быть успешным (36,4\%), смелость (18,2\%), сильный $(13,6 \%)$, мужественный $(13,6 \%)$, добрый $(9,1 \%)$.

Установки относительно поведения выражаются в следующем: доверие $(22,7 \%)$, забота $(22,7 \%)$, уважение $(18,2 \%)$, любовь $(13,6 \%)$, здоровье $(9,1 \%)$, счастье $(9,1 \% \%)$.

Сравнительный анализ полоролевых стереотипов о поведении и качествах у девочек и мальчиков показал следующие результаты, представленные на рисунке 6.

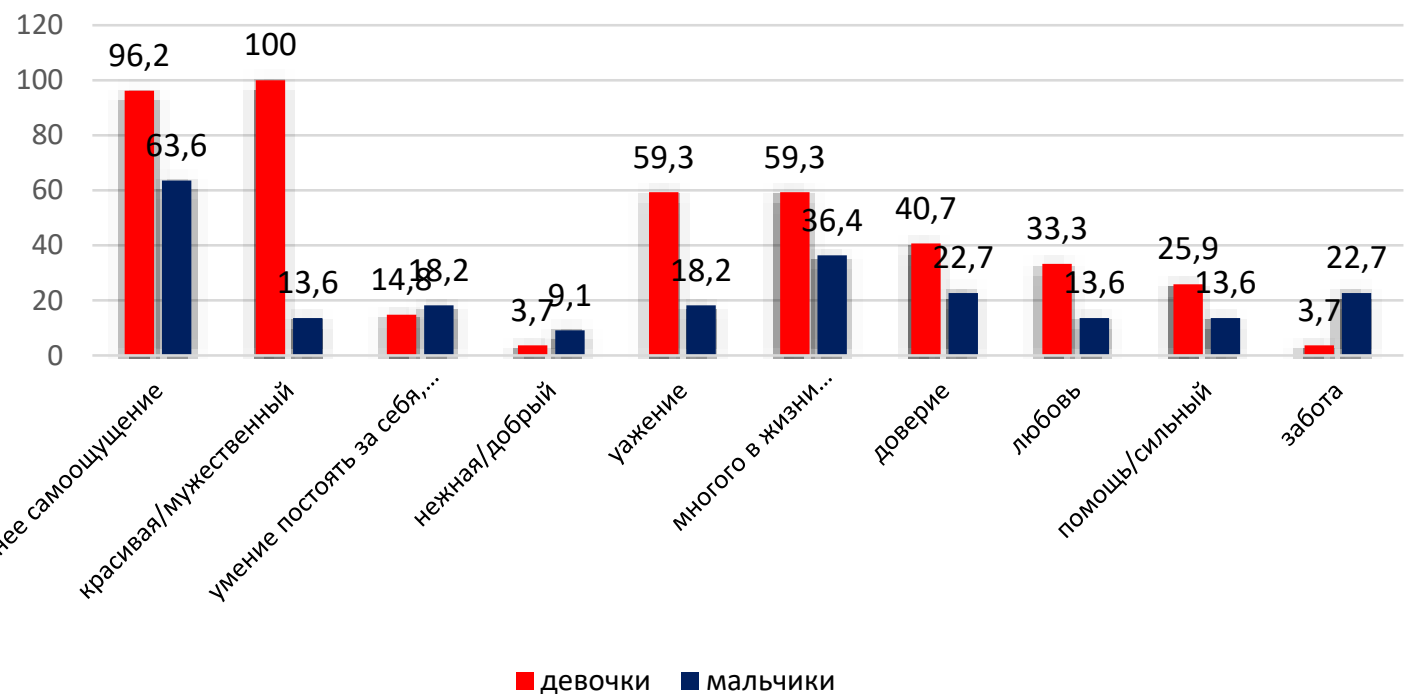

Рисунок 6. Сравнительный анализ полоролевых стереотипов о поведении и качествах у девочек и мальчиков, \%

На рисунке 6 мы видим сравнительный анализ наиболее выраженных критериев полоролевых стереотипов о поведении и качествах у девочек и мальчиков. Так, внутреннее самоощущение как принадлежность к своему 
гендеру более выражено у девочек $(96,2 \%)$, в то время как мальчики больше сосредоточены на мужских чертах характера.

Критерии качеств характера, которыми должны обладать девочки и мальчики, распределились следующим образом. На характеристиках внешности более сосредоточены девочки: красивая (100\%). На чертах характера - смелость $(18,2 \%)$, добрый $(9,1 \%)$ - мальчики сосредоточены немного больше девочек. Но на успешности и проекции на будущее девочки сосредоточены намного больше мальчиков (59,3\%).

Установки относительно поведения выражены в следующих критериях: уважение, доверие, любовь, забота. У девочек ярко выражены уважение (59,3\%), доверие $(40,7 \%)$, любовь $(33,3 \%)$ в сравнении с мальчиками. Забота ярко выражена у мальчиков (22,7\%). Но оказание помощи - у девочек $(25,9 \%)$.

Сравнительные данные говорят о том, что внутреннее самоощущение девочек и мальчиков, хоть и выражено по-разному, но соответствует их гендерной идентичности. Если девочки больше сосредоточены на внутреннем самоощущении как принадлежности к своему гендеру, то мальчики - на мужских чертах характера.

Представления и установки относительно социальных и культурных полоролевых стереотипов о поведении и качествах выражены и у мальчиков, и у девочек. Но вместе с тем, девочкам характерна такая мускулинная черта характера, как «многого в жизни добьюсь», т.е. целеустремленность. В то время как мальчикам - феминная черта характера - добрый.

Степень приверженности гендерным стереотипам у девочек - в норме; у мальчиков - в норме, но важно отметить, что несколько мальчиков находятся в трудной жизненной ситуации и выполнять социальные установки относительно стереотипов мужского поведения и мужских качествах им в настоящий период времени достаточно сложно и нелегко.

Особенности гендерной идентичности детей: у девочек маскулинные и феминные характеристики выражены в равной степени; у мальчиков маскулинные характеристики. 
По полоролевому опроснику С.С. Бема мы определили степень выраженности маскулинных и фемининных характеристик девочек и мальчиков и определили их полоролевые типы личности. Результаты представлены на рисунке 7.

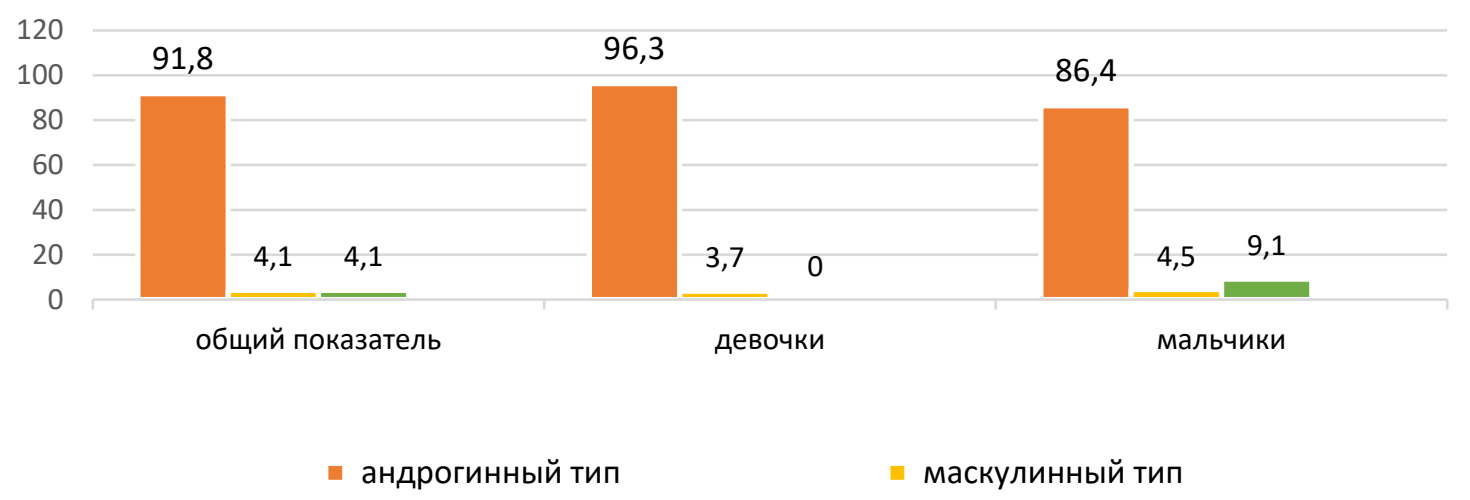

Рисунок 7. Полоролевые типы личности и степень выраженности маскулинных и фемининных характеристик девочек и мальчиков, \%

Из рисунка 7 мы видим, что наиболее выражен андрогинный тип личности (91,8\%). В группе девочек и в группе мальчиков данный тип также выражен наиболее ярко $(96,3 \%$ и 86,4\%). Андрогинный полоролевой тип личности объединяет в себе маскулинные и феминные черты поведения, т.е. мужские и женские черты характера: агрессивность, напористость, рискованность и мягкость, нежность, застенчивость одновременно.

В группе девочек незначительно выражен маскулиный тип личности (3,7\%), т.е. черты характера, которые принято считать мужскими: стремление к доминированиею, грубость, рискованность. Другие типы не выражены.

В группе мальчиков незначительно выражены маскулиный тип $(4,5 \%)$ и фиминный тип личности (9,7\%). При фиминном типе личности мальчикам свойственны черты характера, которые принято считать женскими: застенчивость, нежность, эмоциональность. Недифференцированный тип не выражен, который не предусматривает стабильного выбора стратегии поведения в группе. 
Сравнительный анализ показывает незначительные различия в группе мальчиков и группе девочек. Полоролевой тип личности, наиболее выраженный в поведении, у девочек и мальчиков - андрогинный.

По опроснику «Кто Я?» М. Куна и Т. Макпартленда мы выявили роли гендерных характеристик в структуре Я-концепции личности девочек и мальчиков и изучили содержательные характеристики идентичности их личности. Результаты представлены на рисунках 8-10.

Данные в рисунках представлены не в процентных показателях, а в количественных, с использованием метода контент-анализа.

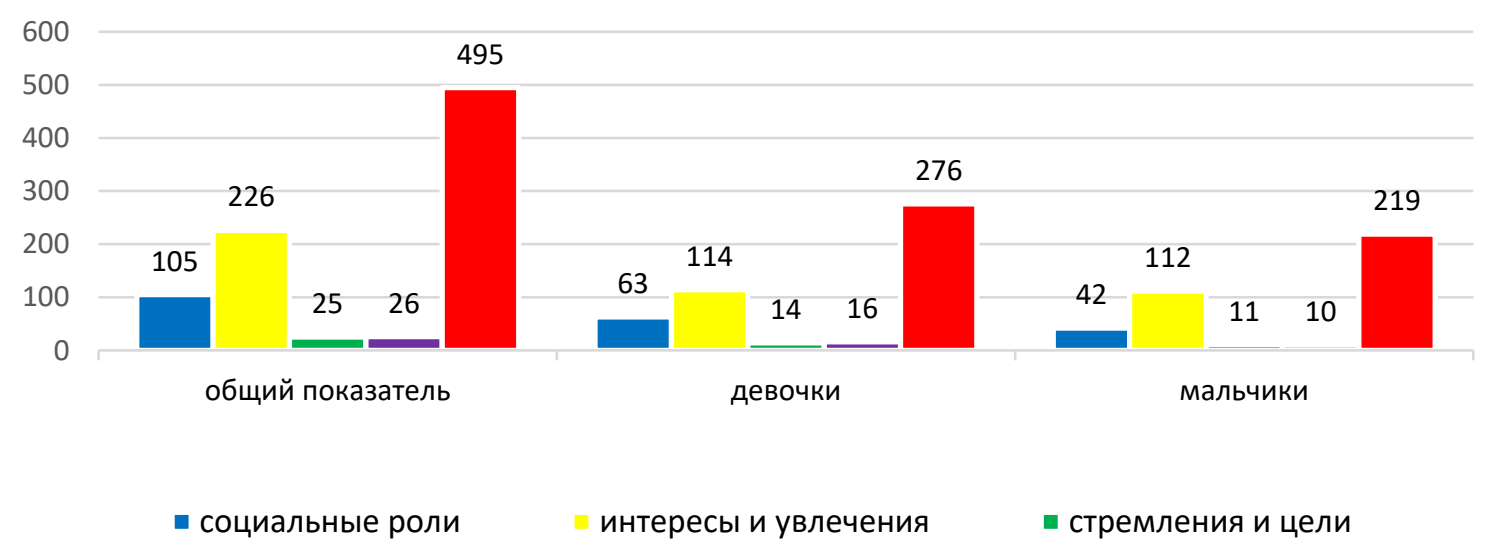

Рисунок 8. Роли гендерных характеристик в структуре Я-концепции личности девочек и мальчиков, \%

Вопрос «Кто я?» связан с характеристиками собственного восприятия человеком самого себя, т.е. с его образом Я. Отвечая на вопрос «Кто я?», девочки и мальчики указывают роли и характеристики-определения, с которыми они себя соотносят, идентифицируют, т.е. с социальным статусом и теми чертами, которые, по их мнению, связываются с ними.

Из рисунка 8 мы видим, что наиболее выражена категория «личная идентичность» и у девочек, и у мальчиков. Менее выражена категория «интересы и увлечения». Незначительно выражены категории «социальные роли», «стремления и цели» и «самооценка». 
Сравнительный анализ показывает незначительные различия в группе мальчиков и группе девочек по всем категориям ролей гендерных характеристик в структуре Я-концепции личности. Наиболее выражена у мальчиков и девочек характеристика «личностная идентичность».

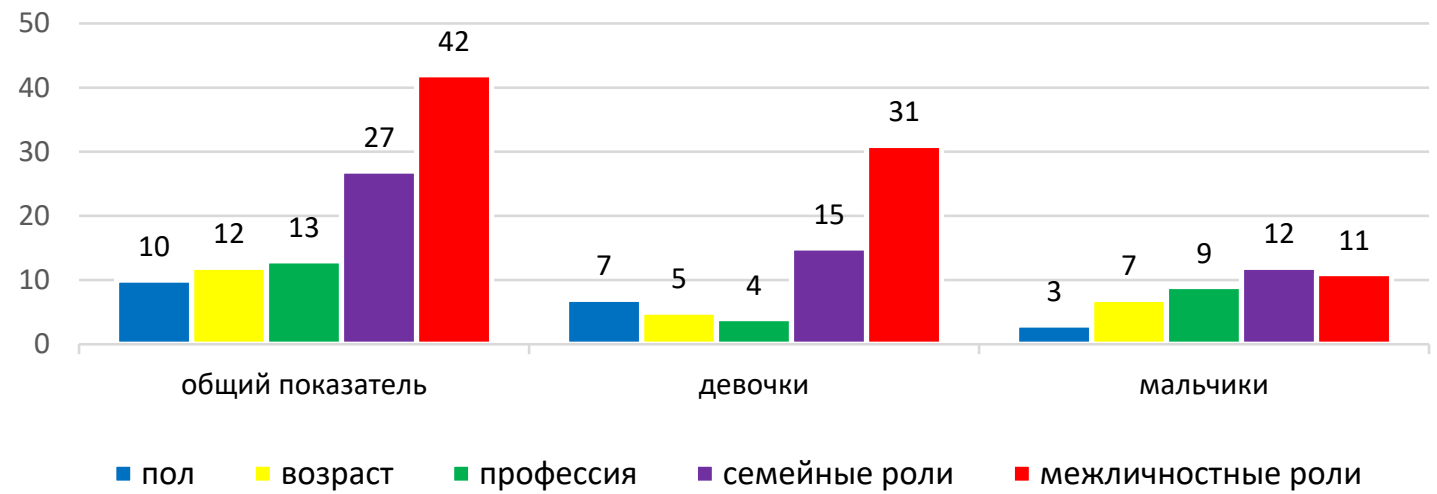

Рисунок 9. Содержательные характеристики социальных ролей девочек и мальчиков, \%

Из рисунка 9 мы видим содержательные характеристики категории «социальные роли» девочек и мальчиков. Наиболее выражен критерий «межличностные роли» и незначительно выражены критерии «профессия», «возраст» и «пол». Если у девочек наиболее выражен критерий «межличностные роли», то у мальчиков все содержательные характеристики социальных ролей выражены примерно в равной степени.

В самоописаниях присутствовала характеристика, обозначающая пол (я мальчик/ девочка), порядок ее упоминания - первые два места. Это свидетельствует о значимости этой характеристики в структуре Я-концепции личности (10 человек: 7 девочек и 3 мальчика).

Сравнительный анализ показывает значительные различия в категории «межличностные роли». По остальным категориям различия незначительные. 


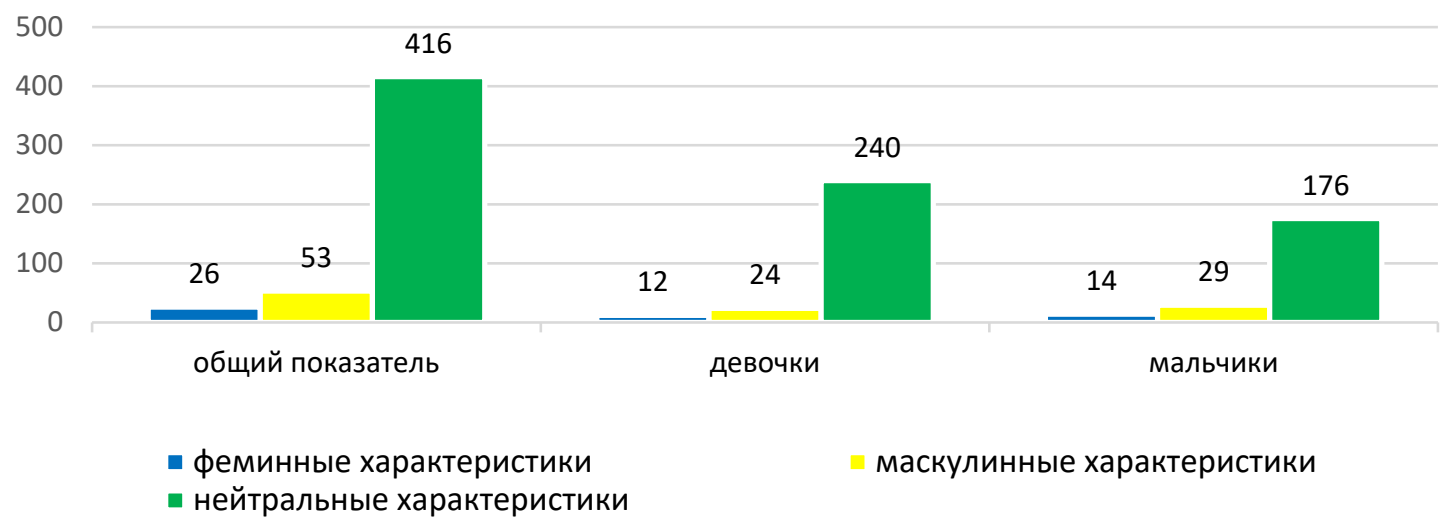

Рисунок 10. Содержательные характеристики личностной идентичности девочек и мальчиков, \%

Из рисунка 10 мы видим содержательные характеристики категории «личностная идентичность» девочек и мальчиков. Наиболее выражен критерий «нейтральные характеристики» и незначительно выражены критерии «маскулинные характеристики» и «феминные характеристики».

Сравнительный анализ показывает значительные различия в категории «нейтральные характеристики». Несмотря на значительные различия, данный критерий ярко выражен и у девочек, и у мальчиков. По остальным категориям различия незначительные.

Полученные данные по опроснику «Кто Я?» М. Куна и Т. Макпартленда совпадают с результаты по полоролевому опроснику С.С. Бема.

Таким образом, проведенное нами исследование с целью изучения психологических особенностей гендерной социализации детей в детском доме в условиях карантина позволило сделать следующие выводы:

1. Внутреннее самоощущение детей, их представления и установки относительно социальных и культурных стереотипов о поведении и качествах представителей разных гендеров выражены в соответствии с полом ребенка. Внутреннее самоощущение как принадлежность к своему гендеру более выражено у девочек (96,2\%), в то время как мальчики больше сосредоточены на мужских чертах характера; 
2. 9,1\% мальчиков находятся в трудной жизненной ситуации и выполнять социальные установки относительно стереотипов мужского поведения и мужских качествах им в настоящий период времени достаточно сложно и нелегко;

3. Представления и установки относительно социальных и культурных полоролевых стереотипов о поведении и качествах выражены в норме и у мальчиков, и у девочек. Девочкам характерна такая маскулинная черта характера, как «многого в жизни добьюсь», т.е. целеустремленность. В то время как мальчикам - феминная черта характера - добрый;

4. Наиболее выражен такой полоролевой тип личности в группе мальчиков и в группе девочек, как андрогинный тип личности, который объединяет в себе маскулинные и феминные черты поведения личности;

5. Роли гендерных характеристик в структуре Я-концепции личности имеют незначительные различия в группе мальчиков и группе девочек по всем категориям.

Таким образом, отклонений в гендерной социализации детей не выявлено.

В мае 2021 г. мы провели дополнительное тестирование с целью определения самооценки и некоторых личностных особенностей поведения девочек и мальчиков, чтобы: 1) выявить корреляционные связи и определить степень влияния самооценки на полоролевой тип личности и гендерные характеристики в структуре Я-концепции; 2) определить поведенческие факторы, влияющие на гендерную социализацию.

Для дополнительного тестирования девочек и мальчиков исследуемой группы мы использовали методики: Тест-опросник «Определение уровня самооценки» С.В. Ковалёва; Методика «Индикатор копинг-стратегий»; Методика акцентуации характера и темперамента личности Г. Шмишека, К. Леонгарда.

Тест-опросник «Определение уровня самооценки» С.В. Ковалёва был использован с целью определения самооценки девочек и мальчиков в 
исследуемой группе: завышенная, заниженная или адекватная самооценка и возможного влияния самооценки на гендерную социализацию.

Методика «Индикатор копинг-стратегий» была использована с целью доминирующих копинг-стратегий мальчиков и девочек и определения поведенческих факторов, влияющих на их гендерную социализацию.

Методика акцентуации характера и темперамента личности Г. Шмишека, К. Леонгарда была использована с целью изучения акцентуированных свойств характера и темперамента мальчиков и девочек, влияющих на их гендерную социализацию.

Мы получили следующие результаты. По тесту-опроснику «Определение уровня самооценки» С.В. Ковалёва мы определили особенности самооценки девочек и мальчиков в исследуемой группе. Результаты представлены на рисунке 11.

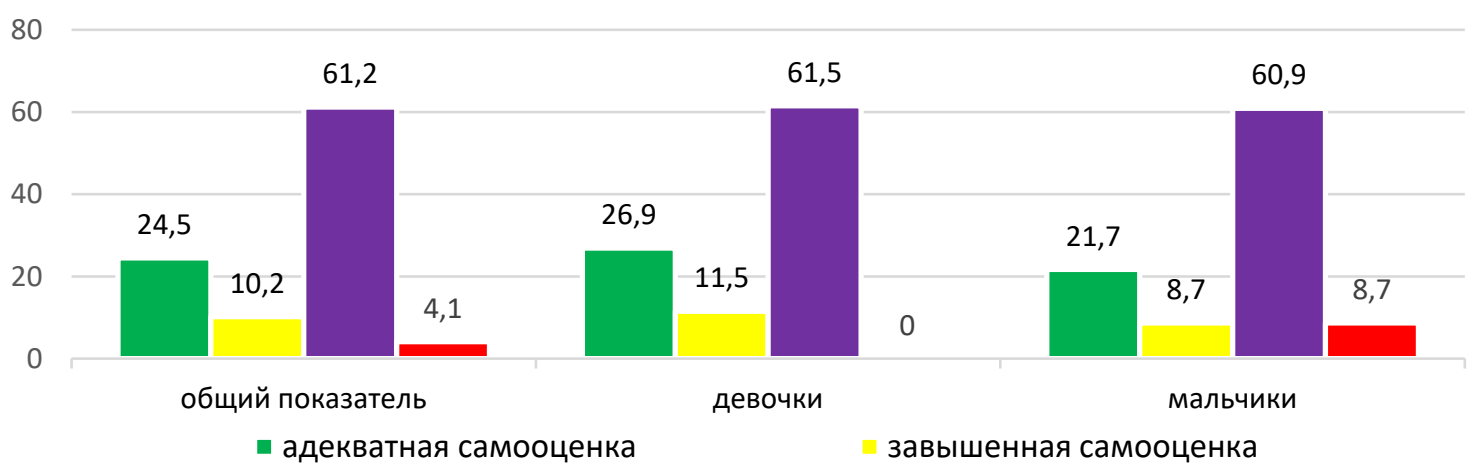

Рисунок 11. Особенности самооценки девочек и мальчиков, \%

Из рисунка 11 мы видим, что общий показатель самооценки в исследуемой группе детей - это заниженная самооценка $(61,2 \%)$, также есть дети с очень низкой самооценкой $(4,1 \%)$. При низкой самооценке дети болезненно переносят критические замечания в свой адрес, стараются подстроиться под мнение окружающих, сильно страдают от застенчивости и неуверенности в себе, недооценивает себя и свои способности без достаточных на то оснований.

Сравнительные данные также показывают высокий процент наличия заниженной самооценки у девочек и мальчиков с незначительным различием 
(61,5\% и 60,9\%). Различия наблюдаются в уровне адекватной самооценки (26,9\% девочек и 21,7\% мальчиков), эти дети адекватно реагирует на замечания окружающих, реально оценивает свои способности и возможности. Завышенная самооценка больше проявляется в группе девочек (11,5\%), т.е. девочки, оценивая свои способности и возможности, преувеличивают их. Очень низкая самооценка характерна только группе мальчиков $(8,7 \%)$, они неуверенны в себе, очень тревожны и сильно занижают свои способности и возможности.

По методике «Индикатор копинг-стратегий» мы определили доминирующие копинг-стратегии мальчиков и девочек: стратегия разрешения проблем, стратегия поиска социальной поддержки и стратегия избегания. Результаты представлены на рисунках 12-14.

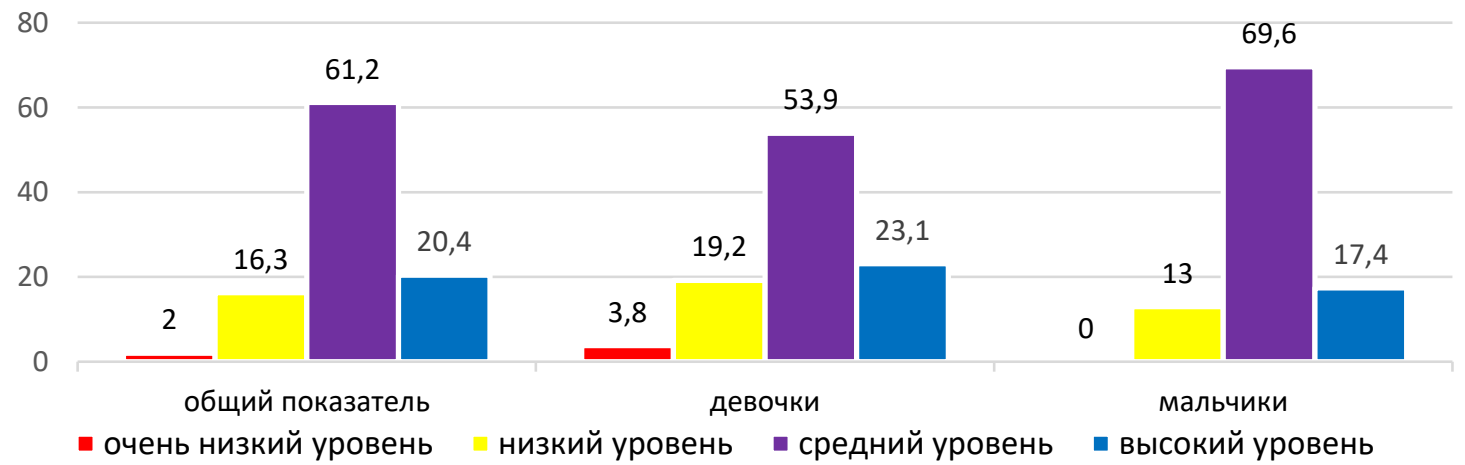

Рисунок 12. Особенности проявления стратегии разрешения проблем у девочек и мальчиков, \%

Из рисунка 12 мы видим, что общий показатель стратегии разрешения проблем у девочек и мальчиков выражен на среднем уровне $(61,2 \%)$. Стратегия разрешения проблем - это активная поведенческая стратегия, при которой человек старается использовать все имеющиеся у него личностные ресурсы для поиска возможных способов эффективного разрешения проблемы.

Сравнительные данные показывают незначительные различия по всем уровням проявления данной стратегии. У мальчиков более ярко выражен средний уровень (69,6\%), в то время как у девочек больше выражены высокий 
$(23,7 \%)$, низкий $(19,2 \%)$ и очень низкий $(3,8 \%)$ уровни стратегии разрешения проблем.

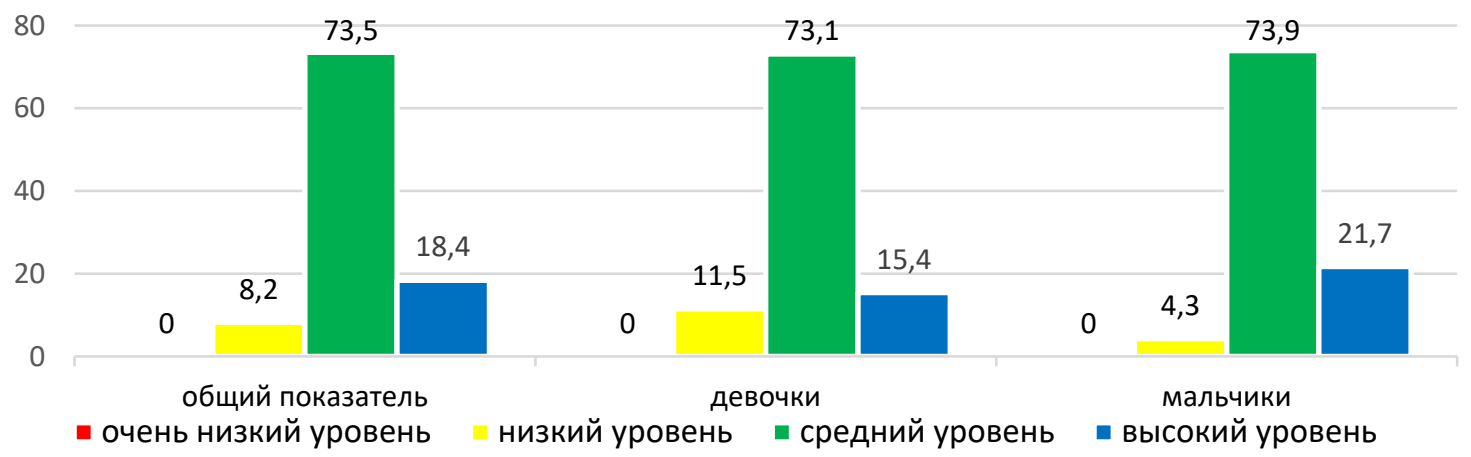

Рисунок 13. Особенности проявления стратегии поиска социальной поддержки у девочек и мальчиков, \%

Из рисунка 13 мы видим, что общий показатель стратегии поиска социальной поддержки у девочек и мальчиков выражен на среднем уровне (73,5\%). Стратегия поиска социальной поддержки — это активная поведенческая стратегия, при которой человек для эффективного разрешения проблемы обращается за помощью и поддержкой к окружающей его среде: семье, друзьям, значимым другим.

Сравнительные данные показывают незначительные различия по всем уровням проявления данной стратегии. У мальчиков более выражен высокий уровень $(21,7 \%)$, в то время как у девочек больше выражен низкий уровень (11,5\%) стратегии поиска социальной поддержки.

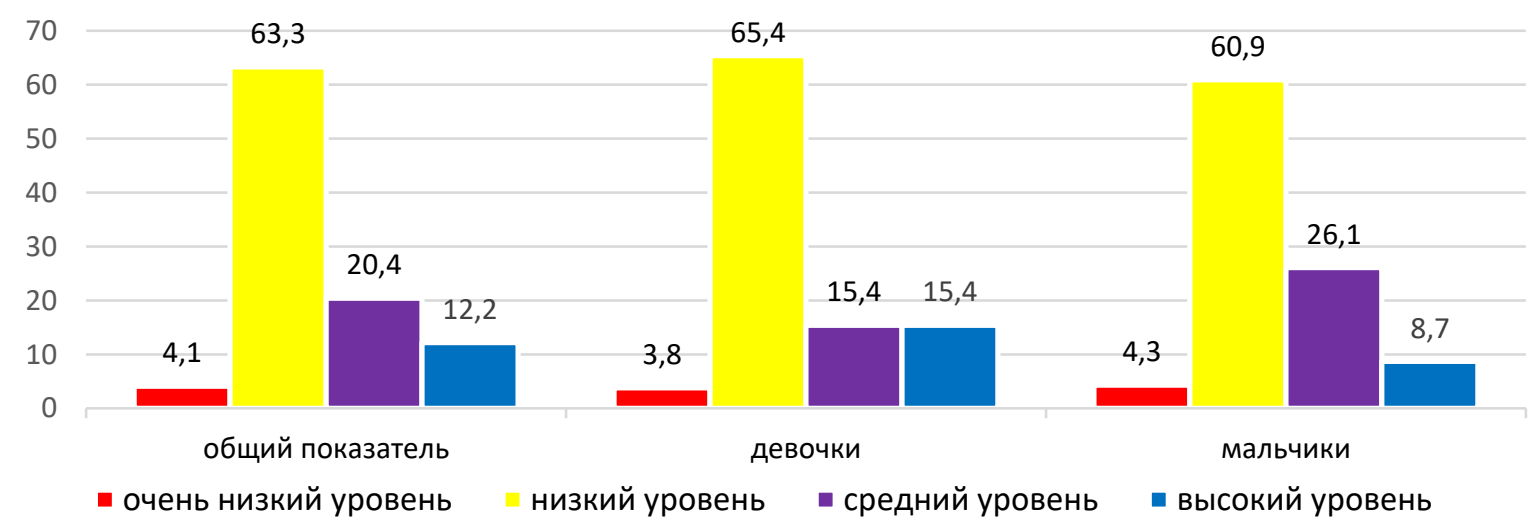

Рисунок 14. Особенности проявления стратегии избегания у девочек и мальчиков, \% 
Из рисунка 14 мы видим, что общий показатель стратегии избегания у девочек и мальчиков выражен на низком уровне (63,3\%). Стратегия избегания это поведенческая стратегия, при которой человек старается избежать контакта с окружающей его действительностью, уйти от решения проблем.

Сравнительные данные показывают незначительные различия по всем уровням проявления данной стратегии. У мальчиков более выражен средний уровень (26,1\%), в то время как у девочек больше выражен высокий уровень $(15,4 \%)$ стратегии избегания.

Таким образом, стратегия избегания — это одна из ведущих поведенческих стратегий при формировании дезадаптивного поведения. Она направлена на преодоление или снижение дистресса человеком. Использование этой стратегии обусловлено недостаточностью развития личностно-средовых копинг-ресурсов и навыков активного разрешения проблем. Однако она может носить адекватный либо неадекватный характер в зависимости от конкретной стрессовой ситуации, возраста и состояния ресурсной системы личности.

Наиболее эффективным является использование всех трех поведенческих стратегий в зависимости от ситуации. В некоторых случаях человек может самостоятельно справиться с возникшими трудностями, в других ему требуется поддержка окружающих, в-третьих он просто может избежать столкновения с проблемной ситуацией, заранее подумав о ее негативных последствиях.

Данные показывают, что наиболее выражена в исследуемой группе стратегия поиска социальной поддержки, менее выражена стратегия избегания. Все три стратегии более выражены в группе мальчиков.

По методике акцентуации характера и темперамента личности $Г$. Шмишека, К. Леонгарда мы определили акцентуированные свойства характера и темперамента мальчиков и девочек. Результаты представлены на рисунке 15. 


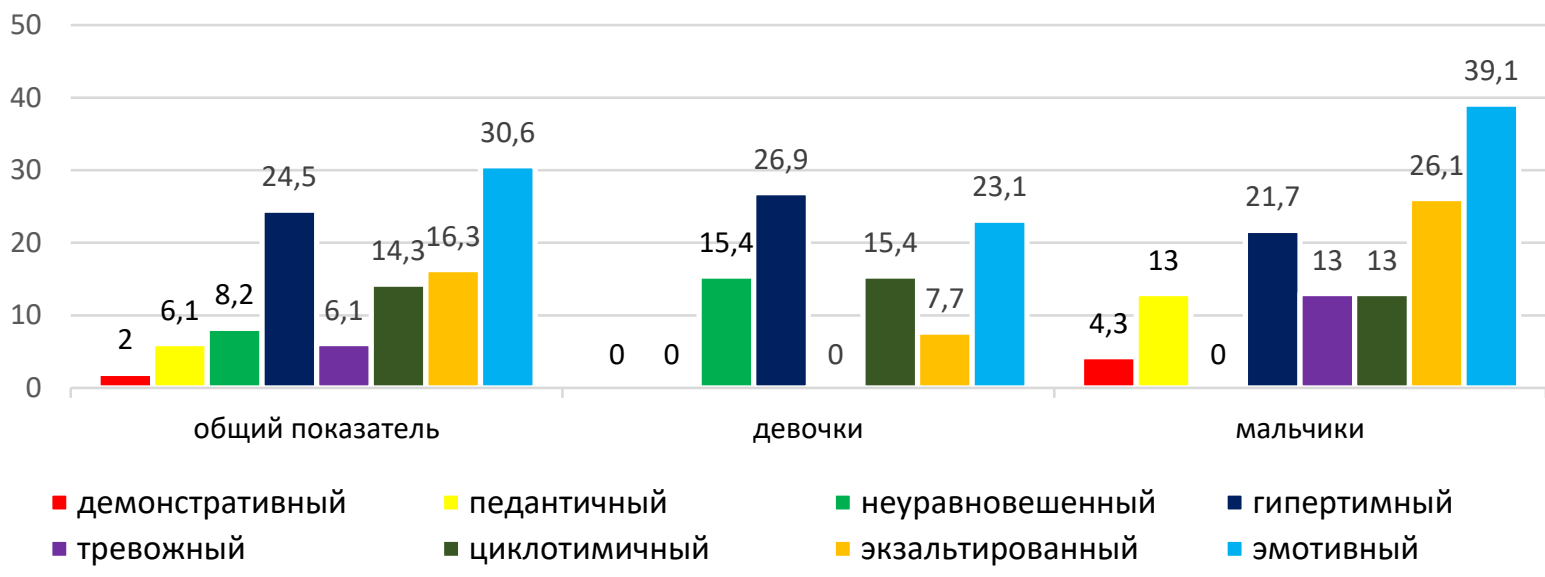

Рисунок 15. Особенности проявления акцентуаций характера и темперамента у девочек и мальчиков, \%

Из рисунка 15 мы видим, что из 10 типов акцентуаций, выражены 8. Не выражены застревающий и дистимичный типы: умеренная общительность, занудливость, склонность к нравоучениям и подавленность настроения, медлительность, слабость волевых усилий. Наиболее ярко выражены эмотивный тип (30,6\%) и гипертимный тип (24,5\%): эмоциональность, чувствительность, тревожность и большая подвижность, общительность, болтливость, выраженность жестов.

Сравнительные данные показывают значительные различия по некоторым критериям в группах мальчиков и девочек. У мальчиков более выражены эмотивный тип (39,1\%), экзальтированный тип $(26,1 \%)$, тревожный (13\%), педантичный тип (13\%). У девочек более выражен неуравновешенный тип (15,4\%). То есть мальчикам характерны такие черты характера, как: инертность психических процессов, долгие переживания травмирующих событий, в конфликты вступают редко, очень сильно реагируют на любое проявление нарушения порядка, аккуратны, с охотой уступает лидерство другим людям; робость, пугливость, способность восторгаться, восхищаться, улыбчивость, ощущение счастья, радости, наслаждения; эмоциональность, чувствительность, тревожность, болтливость, боязливость, гуманность, сопереживание другим людям или животным, отзывчивость, мягкосердечность. Девочкам характерны такие черты характера, как: повышенная импульсивность, 
грубость, занудство, угрюмость, гневливость, склонность к хамству и брани, к конфликтам.

С целью рассчитать, как взаимосвязаны между собой исследуемые признаки мы провели корреляционный анализ. Для расчета корреляционных связей мы выбрали коэффициент ранговой корреляции $r$ - Spearman, т.к. признаки измерены в порядковой шкале. Взаимодействие данных факторов является статистически достоверным (p <0,05). Результаты представлены на рисунке 16.

\begin{tabular}{|c|c|c|c|c|c|c|c|c|c|c|c|c|c|c|c|c|c|}
\hline \multirow[b]{2}{*}{ Variable } & \multicolumn{17}{|c|}{$\begin{array}{l}\text { Spearman Rank Order Correlations (Spreadsheet2) } \\
\text { MD pairwise deleted } \\
\text { Marked correlations are significant at } p<, 05000\end{array}$} \\
\hline & Var1 & Var2 & Var3 & Var4 & Var5 & Var6 & Var7 & Var8 & Var9 & Var10 & Var11 & Var12 & Var13 & Var14 & Var15 & $\begin{array}{c}\text { NewVa } \\
r\end{array}$ & $\begin{array}{c}\text { NewVa } \\
r\end{array}$ \\
\hline Var1 & 1,000000 & 0,765690 & 0,626840 & 0,033004 & $-0,113847$ & 0,049655 & 0,118600 & 0,046697 & 0,001123 & 0,018774 & 0,130052 & 0,118096 & 0,168194 & $-0,083626$ & $-0,003768$ & \begin{tabular}{|l|l|}
3 & 0,154014
\end{tabular} & $-0,137030$ \\
\hline Var2 & & 1,000000 & 0,046120 & 0,032560 & $-0,029513$ & 0,166789 & 0,176055 & 0,033230 & 0,029132 & 0,021527 & 0,170419 & 0,155114 & + 0,085639 & $-0,157342$ & $-0,054977$ & 70,042230 & $-0,119739$ \\
\hline Var3 & & & 1,000000 & 0,052784 & $-0,051561$ & 0,100377 & 0,085043 & 3 0,019854 & 0,121456 & 0,103233 & 0,060264 & 0,011772 & 0,244583 & 0,025715 & $-0,040065$ & \begin{tabular}{|l|l|}
5 & 0,065043
\end{tabular} & $-0,162626$ \\
\hline Var4 & & & & 1,000000 & \begin{tabular}{|l|}
0,064019 \\
\end{tabular} & 0,188659 & 0,039159 & 0,090686 & 0,067697 & 0,015632 & 0,050516 & 0,231934 & t 0,048117 & 0,021591 & 0,353637 & $7 \quad 0,134804$ & $-0,044801$ \\
\hline Var5 & & & & & 1,000000 & 0,645723 & 0,443206 & 0,032930 & 0,048654 & 0,144835 & \begin{tabular}{l|l}
0,000157 \\
\end{tabular} & 0,279933 & 30,021995 & $-0,024494$ & $-0,001353$ & $3 \cdot 0,096629$ & $-0,106064$ \\
\hline Var6 & & & & & & 1,000000 & 0,490811 & 0,119310 & 0,104405 & 0,064797 & 0,080711 & 0,089035 & 0,035566 & $-0,082107$ & 0,131152 & \begin{tabular}{|l|l|l}
2 & 0,034669
\end{tabular} & $-0,091918$ \\
\hline Var7 & & & & & & & 1,000000 & 0,120812 & 0,105218 & 0,124716 & 0,011132 & 0,082206 & \begin{tabular}{l|l} 
& 0,004964
\end{tabular} & 0,016950 & \begin{tabular}{|l|}
0,185174 \\
\end{tabular} & $4 \quad 0,009326$ & $-0,012222$ \\
\hline Var8 & & & & & & & & 1,000000 & 0,349018 & 0,053614 & 0,163956 & 0,467992 & 0,391099 & 0,014274 & 0,428789 & 9 0,097084 & 0,241881 \\
\hline Var9 & & & & & & & & & 1,000000 & 0,107683 & \begin{tabular}{l|l}
3 & 0,346254
\end{tabular} & $\begin{array}{l}0,273906 \\
\end{array}$ & 0,214295 & $-0,048276$ & 0,411807 & 70,393469 & 0,524502 \\
\hline Var10 & & & & & & & & & & 1,000000 & 0,428022 & $-0,052540$ & 0,278795 & 0,321053 & 0,012335 & \begin{tabular}{|l|l|}
5 & 0,317934
\end{tabular} & 0,325297 \\
\hline Var11 & & & & & & & & & & & 1,000000 & 0,049985 & 0,357560 & \begin{tabular}{|l|}
0,519526 \\
\end{tabular} & $-0,152234$ & $\begin{array}{l}4 \quad 0,473995 \\
\end{array}$ & 0,226419 \\
\hline Var12 & & & & & & & & & & & & 1,000000 & 0,401156 & $-0,006455$ & 0,425582 & \begin{tabular}{l|l|}
2 & 0,297368
\end{tabular} & \begin{tabular}{l|l}
3 & 0,206688
\end{tabular} \\
\hline Var13 & & & & & & & & & & & & & 1,000000 & \begin{tabular}{|l|}
0,334305 \\
\end{tabular} & $-0,431300$ & \begin{tabular}{|l|l|}
0,127184 \\
\end{tabular} & $-0,119155$ \\
\hline Var14 & & & & & & & & & & & & & & 1,000000 & 0,085890 & 0,450448 & \begin{tabular}{l|l}
3 & 0,221348
\end{tabular} \\
\hline Var15 & & & & & & & & & & & & & & & 1,000000 & 0,247465 & \begin{tabular}{l|l} 
& 0,388862
\end{tabular} \\
\hline NewVar & & & & & & & & & & & & & & & & 1,000000 & 0,353379 \\
\hline NewVar & & & & & & & & & & & & & & & & & 1,000000 \\
\hline
\end{tabular}

Рисунок 16. Результаты корреляционного анализа

Мы выявили (рисунок 16) положительную и отрицательную корреляционные связи между исследуемыми признаками. Так, отрицательная корреляционная связь обнаружена между дистимным и циклотимным типами акцентуации, т.е. тем больше подавленность настроения, тем меньше частая смена настроения и зависимость от внешних событий.

Положительная корреляционная связь обнаружена между большинством исследуемых признаков. Так, например, чем выше самооценка, тем больше выражены частая смена настроения и зависимость от внешних событий. Чем больше выражена стратегия разрешения проблем, тем больше выражены стратегии избегания и поиска социальной поддержки. Чем больше выражена демонстративность поведения, тем больше выражены частая смена настроения, склонность к нравоучениям, общительность, слабостью волевых 
усилий. Чем больше выражены занудливость, настороженность и недоверчивость по отношению к людям, подозрительность, тем больше выражены повышенная импульсивность, грубость, склонность к хамству и к конфликтам, частая смена настроения, способность восторгаться, восхищаться, высокая общительность, эмоциональность, чувствительность, тревожность. Чем больше выражен андрогинный полоролевой тип, тем больше выражены у детей характеристики феминного и маскулинного типов. Чем больше выражены педантичность, аккуратность, тем больше выражены тревожность, робость, пугливость, неуверенность в себе, экзальтированность, эмоциональность, чувствительность, повышенная импульсивность, грубость. Чем больше выражены повышенная импульсивность, грубость, тем больше выражены тревожность, робость, пугливость, экзальтированность, пессимистическое отношение к будущему, заниженная самооценка. Чем больше выражены общительность, хорошее настроение, тем больше выражены экзальтированность, пессимистическое отношение к будущему, заниженная самооценка, частая смена настроения. Чем больше выражено пессимистическое отношение к будущему, заниженная самооценка, тем больше выражена тревожность.

Таким образом, мы обнаружили, что самооценка зависит от частой смены настроения и от внешних событий. Копинг-стратегии взаимосвязаны между собой и влияют друг на друга. Полоролевые типы (андрогинный, феминный и маскулинный) также взаимосвязаны между собой и влияют друг на друга. Частая смена настроения зависит от демонстративного поведения, настороженности и недоверчивости по отношению к людям, общительности. Общительность зависит от демонстративного поведения, настороженности и недоверчивости по отношению к людям, подозрительности, заниженной самооценки и пессимистического отношения к будущему. Заниженная самооцена зависит от педантичности, повышенной импульсивности, грубости и пессимистического отношения к будущему, тревожности. Настороженность и недоверчивость по отношению к людям зависят от повышенной 
импульсивности, грубости, эмоциональности, чувствительности и тревожности. Тревожность зависит от педантичности, повышенной импульсивности, грубости. Эмоциональность, повышенная импульсивность и грубость зависят от педантичности, пессимистического отношения к будущему.

Данные результаты свидетельствуют о том, что исследуемые признаки взаимосвязаны между собой следующим образом. Копинг-стратегии взаимосвязаны между собой и влияют друг на друга, также, как и полоролевые типы. Данные критерии включают определенные черты характера. При взаимодействии этих черт, наблюдается положительная и корреляционная связи. Таким образом, изучаемые критерии, выявленные в нашем исследовании, проявляются во влиянии друг на друга, т.е. одна черта характера усиливает или подавляет другую. То есть мы можем предположить, что ребенок с заниженной самооценкой, будет грубым, тревожным, импульсивным и др.

Таким образом, проведенное нами дополнительное исследование с целью выявления корреляционных связей и определения степени влияния самооценки на полоролевой тип личности и гендерные характеристики в структуре Яконцепции, определения поведенческих факторов, влияющих на гендерную социализацию, позволило сделать следующие выводы:

1. У детей выражена заниженная самооценка;

2. Различия в копинг-стратегиях незначительные и проявляются на среднем уровне. У девочек более выражена стратегия поиска социальной поддержки $(73,1 \%)$, у мальчиков более выражены стратегии поиска социальной поддержки (73,9\%) и разрешения проблем $(69,6 \%)$;

3. Акцентуированные свойства характера и темперамента мальчиков и девочек показывают значительные различия по некоторым критериям. У мальчиков более выражены эмотивный, экзальтированный, тревожный и педантичный типы. У девочек более выражен неуравновешенный тип. То есть мальчикам характерны такие черты характера, как: инертность психических процессов, долгие переживания травмирующих событий, робость, пугливость, улыбчивость, эмоциональность, тревожность, гуманность, отзывчивость и др. 
Девочкам характерны такие черты характера, как: повышенная импульсивность, грубость, занудство, угрюмость, гневливость и др.;

4. Полоролевой тип личности и гендерные характеристики взаимосвязаны между собой и влияют друг на друга, т.е. нет прямого влияния на самооценку детей, свойства характера и темперамента. Но каждый полоролевой тип личности включает в себя определенный набор личностных черт, которые, в свою очередь, взаимосвязаны между собой и влияют друг на друга, т.е. одна черта характера усиливает или подавляет другую. При взаимодействии этих черт, наблюдается положительная и корреляционная связи.

В заключении можно отметить, что в исследовании изучены психологические особенности гендерной социализации детей в детском доме в условиях карантина. Отклонений в гендерной социализации детей не выявлено, но личностные характеристики, влияющие на гендерную социализацию выражены по-разному у девочек и мальчиков. 